\title{
FINITE ELEMENT SIMULATION OF HYBRID WELDING PROCESS FOR WELDING 304 AUSTENITIC STAINLESS STEEL PLATE
}

\author{
${ }^{1}$ Amudala Nata Sekhar Babu, ${ }^{2}$ Lakshmana Kishore.T \\ ${ }^{1}$ M.Tech (student), Mechanical Engineering Department, GIET, Andhra Pradesh, India, \\ ${ }^{2}$ Associate Professor, Mechanical Engineering Department, GIET, Andhra Pradesh, India, \\ kartheek_kandhukuri@yahoo.com, tlkishore.giet@gmail.com
}

\begin{abstract}
Although autogenous laser welding has many advantages over traditional welding methods in many applications, still the process has a main disadvantage of poor gap bridging capability, which limits its applicability for wider industrial use. Owing to this limiting factor, a great deal of research work was carried out to overcome this disadvantage by using Arc source with laser welding. The combination of laser and Arc (MIG/TIG) welding processes in a same process zone is known as Hybrid Welding. This process involves very high peak temperature and rapid change in thermal cycle both of which are difficult to measure in real time. In this dissertation work, a 3-dimensional finite element model was developed for the analysis of hybrid welding process. Ansys Parametric Design language (APDL) code was developed for the same. The FEA results were validated with experimental results showing good agreement. Hybrid welding Simulations were carried out for AISI 304 Austenitic stainless Steel plate. The effects of laser beam power, Arc Welding and torch angle on the weld-bead geometry i.e. penetration (DP), welded zone width $(B W)$ were investigated. The experimental plan was based on three factor 5 level central composite rotatable design. Second order polynomial equations for predicting the weld-bead geometry were developed for bead width and depth of penetration. The results indicate that the effect of arc current $(A C)$ on bead width was more than on depth of penetration. Hence, the proposed models predict the responses adequately within the limits of welding parameters being used.
\end{abstract}

Index Terms: Hybrid Welding, Ansys Parametric Design language (APDL), FEA, AISI 304 Austenitic stainless Steel, and Central composite rotatable design

\section{INTRODUCTION}

Hybrid welding is one of the latest advancements in welding technology. The number of applications of this new welding process in the industry is increasing. So, a brief introduction about the process is presented in this chapter. Also the need and objective of the present work is described in detail.

\subsection{Hybrid Welding Process}

It was known for almost thirty years that it is possible to combine a conventional welding arc with a laser beam in a hybrid process, but only recently has it become one of the major research areas in welding technology. When the idea was first suggested many were still unsure of the laser's suitability for industrial use. Now that the high power laser has become established in a number of industrial applications, the possibility of uniting the two welding processes to achieve the advantages of both was much more plausible [1]. Both types of processes have their own characteristics, advantages and disadvantages. The main advantages of the laser welding process are low heat input and high welding speed, typically producing a narrow and deep weld seam, which minimizes thermal distortion. The narrow weld seam leads to a low gap bridging capability and requires an exact joint preparation and clamping whereas MIG welding processes gives a high heat input producing a wide and shallow weld at relatively low welding speeds. However, the arc welding processes are very efficient regarding the addition of filler material and therefore preferred when larger joint gaps are present. In order to gain the advantages of the two processes, the Laser Hybrid Welding process was developed by combining the laser beam welding and arc welding in one single process [2]. The positive synergy effect of the combination of laser and arc is because of the ignition resistance in the evaporated material is reduced and the arc can be ignited more easily. The number of applications of this new welding process in the industry is increasing. A disadvantage with the hybrid process is the great number of process parameters [3].

\subsection{AISI 304 Austenitic Stainless Steels}

Austenitic stainless steel contains a combined total of chromium, nickel and manganese content of $24 \%$ or more with chromium content above $16 \%$ and nickel of above $7 \%$. The chromium provides oxidation resistance and resistance to corrosion while nickel and manganese stabilize the austenite phase sufficiently to retain most or all of it when the steel is 
cooled rapidly to room temperature. The austenitic stainless steel is usually the most corrosion resistant of all the stainless steels and thus finds wide use in chemical plants. Those steels are grouped into AISI 200 and AISI 300 series. The austenitic stainless steels have generally low yield strength and high ultimate tensile strength; hence they are very ductile.

AISI type 304 stainless steel used in the present study have many advantages such as low thermal conductivity, high resistance to corrosion and high stability at elevated temperatures and also it is superior absorber of laser light. Due to these advantages, it is used in numerous industries, including electronics, medical instruments, home appliances, automotive and specialized tube industry. It has excellent forming and welding characteristics.

The properties of a typical stainless steel sheet are given in Table 1.1. A major concern, when welding austenitic stainless steel, is the susceptibility to solidification and liquation cracking. The materials can be very resistant to these forms of high temperature cracking, if the material is compositionally balanced such that solidification behavior and microstructure is controlled to ensure that the weld metal contain the right volume \% ferrite. This improves resistance to microfissuring and hot cracking and also enhances resistance to stress corrosion cracking.

Table 1.1 Properties of AISI 304 Steel

\begin{tabular}{|l|l|l|l|l|l|}
\hline $\begin{array}{l}\text { Tensile } \\
\text { Strengt } \\
\text { h }\end{array}$ & $\begin{array}{l}\text { Yield } \\
\text { Strengt } \\
\mathrm{h}\end{array}$ & $\begin{array}{l}\text { Densit } \\
\mathrm{y}\end{array}$ & $\begin{array}{l}\text { Meltin } \\
\mathrm{g} \text { Point }\end{array}$ & $\begin{array}{l}\text { Therm } \\
\text { al } \\
\text { Condu } \\
\text { ctivity }\end{array}$ & $\begin{array}{l}\% \\
\text { elongat } \\
\text { ion }\end{array}$ \\
\hline $\begin{array}{l}515 \\
\mathrm{MPa}\end{array}$ & $\begin{array}{l}205 \\
\mathrm{MPa}\end{array}$ & $\begin{array}{l}8000 \\
\mathrm{~kg} / \mathrm{m}^{3}\end{array}$ & $\begin{array}{l}1400- \\
1450 \\
{ }^{\circ} \mathrm{C}\end{array}$ & $\begin{array}{l}16.2 \\
\mathrm{~W} / \mathrm{m}^{\circ} \\
\mathrm{K} \text { at } \\
100^{\circ} \mathrm{C}\end{array}$ & $20-40$ \\
\hline
\end{tabular}

\subsection{Need For The Work}

The need for joining materials with higher welding speeds and good quality to improve the industrial output increased with the advancement in technology. Unfortunately, due to the small spot size of the laser, it has difficulties in some welding applications because of insufficient gap bridging capabilities as well as the high precision that is required during positioning. These shortcomings were overcome by combining the laser with an arc welding technique such as gas metal arc welding (GMAW) or gas tungsten arc welding (GTAW). In Hybrid welding, the depth of penetration and the bead width are the two important factors which influence the mechanical properties of the weldment. So, it was necessary to study the effects of process parameters on these factors.
With the utmost computing facilities available today, any process or physical phenomena can be modeled easily. Taking all these factors into consideration, it was decided to develop finite element model to predict the weld bead geometry. The analytical implementation of the model in simulation programs allows determination and quantification of the effect of process parameters on the weld quality. Hence, the study on these effects will help the user industry for effective application of Hybrid welding in the fabrication of thin and thick stainless steel materials.

\subsection{Objective}

The main objectives of the study were

1) To develop an APDL code in ANSYS 10.0 to perform the transient analysis and to simulate the Hybrid Laser - MIG welding process.

2) To development of mathematical models in order predict the bead geometry from the input process variables.

3) To study the effects of various process parameters on weld bead dimensions.

\section{INTRODUCTION TO HYBRID WELDING}

A strong drive for the development of higher productivity welding processes that meet the stringent design requirements had shown a seed for the origin a new welding technique known as Hybrid welding [1]. Hybrid (Laser-MIG/TIG) welding processes, in which a laser and an arc are combined in the same process zone, can offer a number of benefits over autogenous laser welding, including increased productivity and a tolerance to fit up comparable with arc welding. The laser-MIG hybrid welding process is up to $50 \%$ faster compare to autogenous laser welding and $75 \%$ faster than MIG welding [2]. Both types of processes have their own characteristics, advantages and disadvantages. Now that the high power laser has become established in a number of industrial applications, the possibility of uniting the two welding processes to achieve the advantages of both was much more plausible.

Laser welding is an interesting process because of the following advantages:

- $\quad$ Good quality: Narrow, deep weld seam
- $\quad$ High completion rates
- $\quad$ Low but consumable costs (no filler required)
results in low and predictable distortion levels
- $\quad$ Reduced post weld rework
- No mechanical contact between the laser
equipment and the workpieces
- Joining of widely dissimilar materials is
possible




\subsection{Hybrid Welding Process Principle}

The focused laser beam impinges on the work piece surface converting its energy into heat. This causes vaporization of the work piece material and formation of a deep vapor-filled capillary, i.e. keyhole, which is stabilized by the pressure of the metal vapor being generated. The power of the arc welding process introduces more energy to the zone of laser beam impingement causing the process gas to be ionized, thus enhancing arc stability. When the two processes are coupled as one process as shown in Fig.2.1, the laser beam and the arc process interact simultaneously in one zone. Laser beam bridges the root followed by the arc process (GMAW). The metal vapor is capable of becoming hotter and forms laserinduced plasma that emerges from the keyhole causing attenuation of the laser beam above the work surface. This is called plasma-shielding effect [4], and its extent depends upon the gas type, electron density, and laser wavelength. In order to reduce the plasma effect, a process gas with high ionization potential, normally helium is used. In hybrid laser-arc welding a laser (CO2 or YAG) is combined to an arc process (TIG, MIG, MAG or plasma).

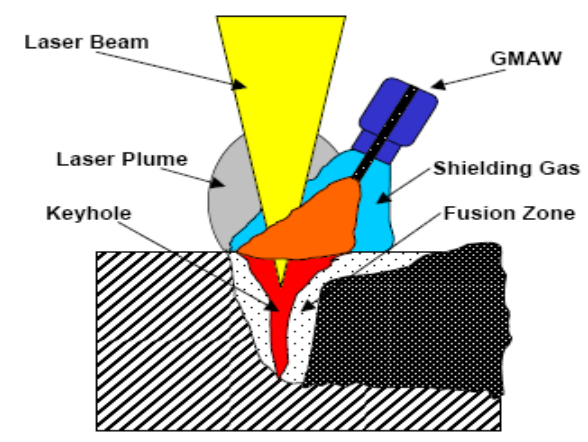

Fig 2.1 Schematic of the Laser -MIG Hybrid welding process

\subsection{Process Parameters:}

\subsubsection{Laser power}

An increase in laser power will generally increase the weld penetration [6]. In the case of hybrid laser-arc welding (as opposed with the laser-only process) this phenomenon is accentuated because the reflectivity of the workpiece metal is reduced when the metal is heated by the arc.

\subsubsection{Welding speed}

The weld penetration increases when the welding speed is decreased because the heat input per unit length of weld is higher. Also the gap filling capability by the filler wire is improved at lower welding speeds (at constant filler wire feeding) [6]. The ratio between welding speed and filler wire feeding is important to the stability of the keyhole and thus for the stability of the process itself.

\subsubsection{Relative arrangement of the laser and the MIG} torch

To get the maximum weld penetration the laser is positioned perpendicularly to the direction of welding. The leading or trailing position of the arc torch is a determining factor for the weld characteristics. For mild steels the arc leading configuration is referred since an increase in penetration is obtained in this way. Also, the distance between the laser and the wire tip is one of the most important parameters to control in hybrid laser-arc welding. A short distance, typically $2 \mathrm{~mm}$ between the laser spot and the filler wire tip has been shown to be favorable for a steady keyhole and for maximum penetration.

\subsubsection{Focal point position}

The maximum weld penetration for the hybrid laser-arc process is generally obtained when the laser beam is focused below the top sheet surface ( 2 to $4 \mathrm{~mm}$ ).

\subsubsection{Angle of electrode}

The penetration of the weld increases with the angle of the electrode to the workpiece surface up to 50 degrees. The gas flow along the welding direction provided by the arc torch deflects the plasma induced by the laser, and reduces the absorption of the laser beam by this plasma when $\mathrm{CO} 2$ lasers are employed. Therefore the angle of electrode to the top surface of the workpiece is often set at around 40-50 degrees.

\subsubsection{Power modulation of the arc welding source}

The arc welding source uses a DC mode rather than an AC mode because the energy input and density are higher in the first case. The arc source is often operated in a pulsed mode since this has been shown to reduce the amount of spatter whilst maintaining a deep penetration of the weld. The welding voltage has been shown not to greatly influence the weld penetration depth, which is mostly dependant on the laser power, but the weld bead gets wider if the welding voltage increases, giving a lower depth to width ratio for a same laser power. The arc voltage (and wire feed rate) will therefore need to be increased for wider fit-up gaps, to avoid any lack of fusion. The welding current is generally matched to the filler wire diameter (higher welding current for higher wire diameter). Considering a given wire diameter and voltage settings it has been shown that an increase in welding current will give a deeper weld, with a higher depth to width ratio.

\section{FINITE ELEMENT MODELING AND SIMULATION OF HYBRID WELDING PROCESS FOR WELDING 316L STEELS}

The study of heat flow and temperature distribution in the parts being welded becomes necessary otherwise may lead to 
failure of the component. Finite element analysis (FEA) was used by many authors to perform welding simulations and to study the thermal history. Modeling of the welding process must account for the specialized effects of the moving weld source and material deposition. The computer based simulations offer the possibility to examine different aspects of the process without having the prototype of the product. The finite element modeling and simulations were performed for welding of stainless steel plates using ANSYS 10.0 software. The commercial finite element code "ANSYS PARAMETRIC DESIGN LANGUAGE", enhanced with user subroutines was used to model weld simulations with great success.

\subsection{Heat Transfer Governing Equation For Welding}

The mathematical formulation for the three-dimensional heat conduction in a domain $\mathrm{D}$ is given as follows:

$\frac{\partial}{\partial x}\left(\mathrm{Kx} \frac{\partial \mathrm{T}}{\partial x}\right)+\frac{\partial}{\partial y}\left(\mathrm{Ky} \frac{\partial \mathrm{T}}{\partial y}\right)+\frac{\partial}{\partial z}\left(\mathrm{Kz} \frac{\partial \mathrm{T}}{\partial z}\right)+Q=\rho c\left(\frac{\partial T}{\partial t}-v \frac{\partial T}{\partial x}\right)$

Where,

$Q \quad=$ power generation per unit volume in

the domain $\mathrm{D}$,

$$
\mathrm{W} \mathrm{m}{ }^{-3}
$$

$\mathrm{Kx}, \mathrm{Ky}, \mathrm{Kz}=$ thermal conductivity in $\mathrm{x}, \mathrm{y}$ and $\mathrm{z}$ directions, $\mathrm{Wm}^{-1} \mathrm{k}^{-1}$

$\begin{array}{ll}c & =\text { specific heat capacity, } \mathrm{J} \mathrm{kg}^{-1} \mathrm{~K}^{-1} \\ \rho & =\text { density of the material, } \mathrm{kg} \mathrm{m}^{-3} \\ \mathrm{t} & =\text { time, } \mathrm{s} \\ v & =\text { velocity of moving source, } \mathrm{ms}^{-1}\end{array}$

\subsection{Assumptions In Finite Element Simulation:}

The following assumptions were made to develop the finite element model,

- The initial temperature of work piece is kept at 303 ${ }^{\mathrm{o}} \mathrm{K}$.

- Work piece is fixed and moving heat source is considered.

- Convection is applied on all surfaces except at the bottom surface.

- Combined radiation and convection are considered by the Vinokurov's empirical relationship, $\mathrm{h}=$ $2.41 \times 10^{-3} \in \mathrm{T}^{1.61}, \mathrm{~W} / \mathrm{m}^{20} \mathrm{C}$.

- Forced convection due to shielding gas flow was not considered.

- Metal deposition rate was kept constant through out the analysis.

\subsection{Finite Element Analysis Procedure:}

The general finite element modeling procedure consists of the following steps.

\section{Preprocessing}

- Element type definition

- Material properties definition

- Building model

Solution

- Defining initial condition

- Applying boundary condition

- Applying load

- Solving for results

Post processing

- Reading result file

- Viewing results

\subsubsection{Preprocessing}

\subsubsection{Selection of element type:}

The size and type of the element are crucial to obtain accuracy of the result and reduction of solution time required for finite element analysis. The element chosen for the analysis is SOLID 70.

\subsubsection{SOLID70 Element Description:}

SOLID70 has a 3-D thermal conduction capability. The element has eight nodes with a single degree of freedom, temperature, at each node. The element is applicable to a 3-D, steady-state or transient thermal analysis. The element also can compensate for mass transport heat flow from a constant velocity field. The geometry of solid 70 is shown in Fig 3.1

\subsubsection{Material properties:}

Stainless steel is the most common structural material for welded fabrication. The temperature-dependent properties of AISI 316L Austenitic stainless steels used for the heat transfer and temperature distribution are shown in Table.3.1. The weldment material properties employed in this work are taken from the data published by Blom and Church [1].

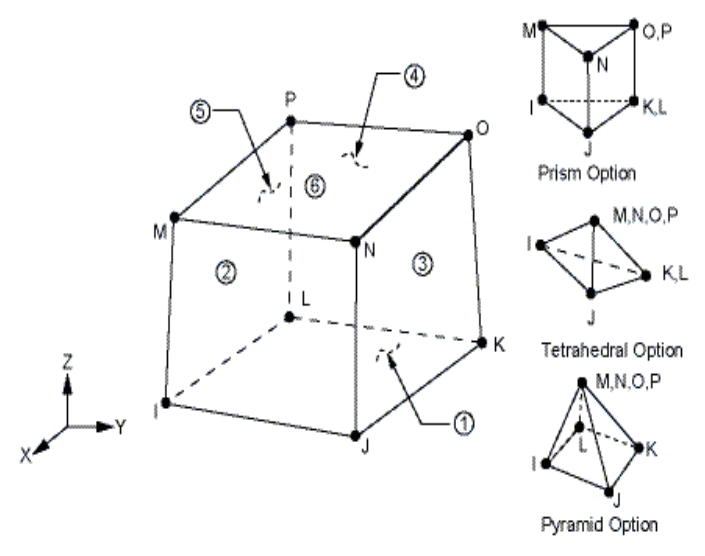

Fig. 3.1 Solid 70 geometry 


\subsubsection{Finite Element Modeling of the weld plate:}

The model for finite element analysis was generated by direct generation technique. Direct generation method is convenient for small and simple models and also provides complete control over the geometry by numbering every node and every element. The weld plate modeled was of $440 \mathrm{~mm}$ in width, $100 \mathrm{~mm}$ in length and $10 \mathrm{~mm}$ thick. Reinforcement on the plate was generated prior to the analysis during modeling. Closer view of the meshed model of the plate shows the reinforcement on its top surface as shown in Fig 3.2. Element Birth and Death concept was employed for metal deposition assuming the deposition to be constant through out the analysis and also the same base plate material was deposited on the plate surface.

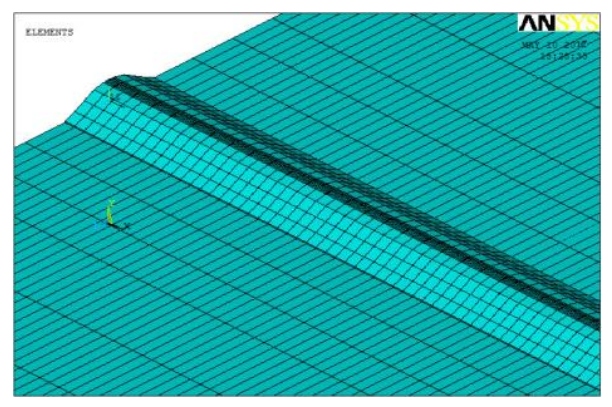

Fig. 3.2 Closer view of meshed model of the plate with reinforment on the top surface

Table 3.1 Temperature Dependent Thermal Properties for AISI 316L Stainless Steel

\begin{tabular}{|c|c|c|}
\hline $\begin{array}{c}\text { Temp } \\
(\mathbf{K})\end{array}$ & $\begin{array}{c}\text { Thermal } \\
\text { Conductivity, } \\
\mathbf{W} / \mathbf{m}^{\mathbf{0}} \mathbf{K}\end{array}$ & $\begin{array}{c}\text { Specific Heat, } \\
\mathbf{J}^{/ \mathbf{K g}^{\mathbf{}} \mathbf{K}}\end{array}$ \\
\hline 200 & 17 & 500 \\
\hline 400 & 19.5 & 530 \\
\hline 600 & 22.5 & 550 \\
\hline 800 & 24 & 570 \\
\hline 1000 & 27 & 585 \\
\hline 1200 & 38.5 & 650 \\
\hline 1400 & 61 & 650 \\
\hline 1600 & 85.5 & 650 \\
\hline 1800 & 118 & 650 \\
\hline 2000 & 141.5 & 650 \\
\hline 2200 & 141.5 & 650 \\
\hline
\end{tabular}

The element sizes are made finer in the weld zone, since the temperature gradient is very high (stress concentration) and coarser elements are used away from the weld centre line. Along the depth direction 5 elements were used. Along the welding direction 125 divisions were made and in the transverse direction 66 divisions were made.

\subsubsection{Application of Thermal Loads:}

Gaussian heat flux was applied on the top surface of the upper layer elements present in the finely meshed zone which were within the vicinity of the laser and MIG source. The heat calculated using Double ellipsoidal model (eqn 3.6) was applied on all the nodes containing the elements in the finer zone. Fig 3.3 shows the plate with Gaussian heat flux applied on the elements.

The load step size $(d x)$ was calculated as follows,

$d x=$ Length of the weld line /total no. of elements on the weld line no. of divisions in each element

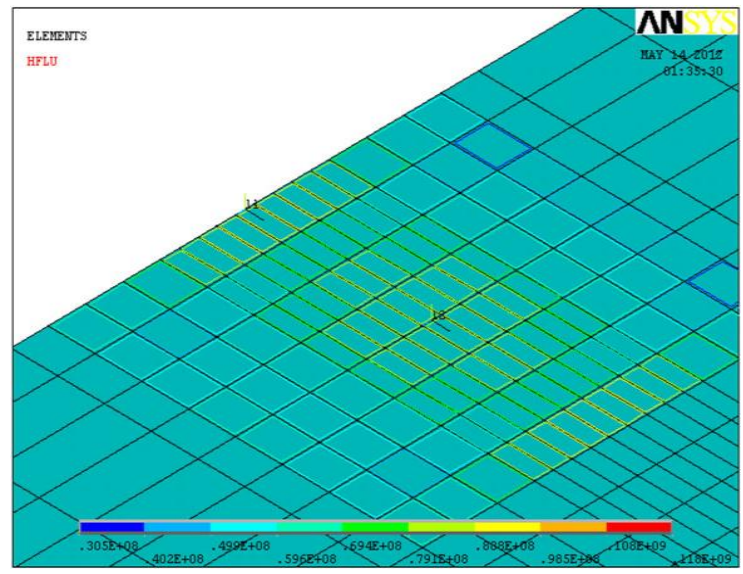

Fig 3.3 Gaussian heat flux distribution on the surface of the elements

\subsubsection{POST PROCESSING:}

In the post processing stage, the temperature contour plots, time temperature plot, diastance-temperature plot, sliced cross section of the weld plate and molten temperature isotherm which indicates weld bead profile were obtained. From the weld bead profile the bead geometry was measured.

\subsubsection{Validation Of The Model:}

The FEA model was validated with the experimental results obtained from work carried out by Rayes [29]. The comparisons of the simulated results with the experimental results obtained are shown in Table 3.2.

\subsubsection{Specifications for Validation model:}

- Plate Dimensions: 100 mm X 440 mm X 10 mm

- Material Used: AISI 316L Stainless Steels

- Diameter of Laser spot: $0.8 \mathrm{~mm}$

- Diameter of Electrode: $1.2 \mathrm{~mm}$

- $\mathrm{MIG}$ torch angle: $30^{\circ}$

- Welding Speed: $1800 \mathrm{~mm} / \mathrm{min}$ 
Fig 3.4 and 3.5 shows the comparison of simulated depth of penetration and bead width respectively with the experimental results showing good agreement. Fig 3.6, 3.7 and 3.8 shows the melting temperature isotherms obtained for arc powers $4000 \mathrm{~W}, 6000 \mathrm{~W}$ and $8000 \mathrm{~W}$ respectively. The increase in bead width with increase in arc power can be clearly noticed

Table 3.2 Comparison of the simulated results with Experimental results

\begin{tabular}{|c|c|c|c|c|c|c|c|}
\hline \multirow{2}{*}{ S.No } & \multirow{2}{*}{$\begin{array}{c}\text { Arc } \\
\text { Pow } \\
\text { er, } \\
\text { watts }\end{array}$} & \multicolumn{3}{|c|}{\begin{tabular}{c}
\multicolumn{3}{c|}{ Depth of } \\
Penetration, mm
\end{tabular}} & \multicolumn{3}{|c|}{ Bead Width, mm } \\
\cline { 3 - 8 } & & $\begin{array}{c}\text { Ex } \\
\mathrm{p}\end{array}$ & FEA & $\begin{array}{c}\text { Erro } \\
\mathrm{r} \%\end{array}$ & $\begin{array}{c}\text { Ex } \\
\mathrm{p}\end{array}$ & FEA & $\begin{array}{c}\text { Error } \\
\%\end{array}$ \\
\hline 1 & 4000 & 7.5 & $\begin{array}{c}6.83 \\
3\end{array}$ & 8.89 & $\begin{array}{c}6 . \\
9\end{array}$ & 6.12 & 11.3 \\
\hline 2 & 5000 & 7.3 & $\begin{array}{c}6.52 \\
1\end{array}$ & $\begin{array}{c}10.6 \\
7\end{array}$ & $\begin{array}{c}7 . \\
4\end{array}$ & 6.66 & 10 \\
\hline 3 & 6000 & 8.2 & $\begin{array}{c}7.01 \\
14.5\end{array}$ & $\begin{array}{c}8 . \\
1\end{array}$ & $\begin{array}{c}6.97 \\
1\end{array}$ & 13.93 \\
\hline 4 & 7000 & 7.9 & $\begin{array}{c}6.96 \\
8\end{array}$ & $\begin{array}{c}11.7 \\
9\end{array}$ & $\begin{array}{c}8 . \\
2\end{array}$ & $\begin{array}{c}7.11 \\
2\end{array}$ & 13.26 \\
\hline 5 & 8000 & 7.8 & $\begin{array}{c}6.80 \\
3\end{array}$ & $\begin{array}{c}12.7 \\
8\end{array}$ & $\begin{array}{c}8 . \\
1\end{array}$ & $\begin{array}{c}7.23 \\
6\end{array}$ & 10.55 \\
\hline
\end{tabular}

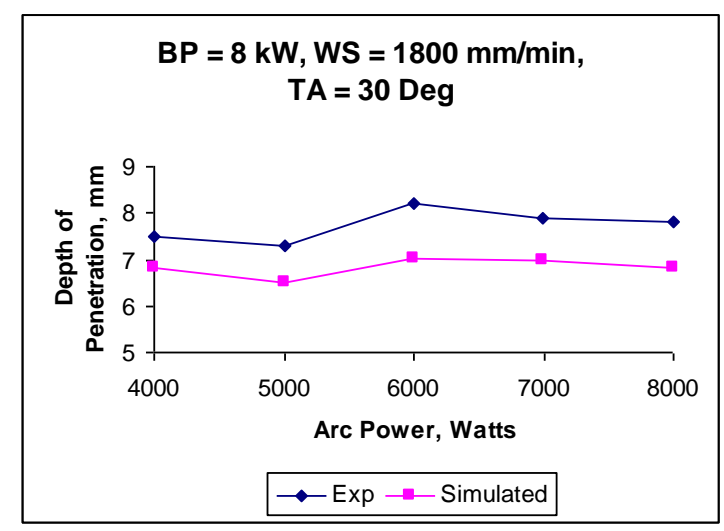

BP-Beam Power, WS- Welding Speed, TA- Torch angle

Fig.3.4 Graph showing comparison between Simulated Depth of Penetration with Experimental results

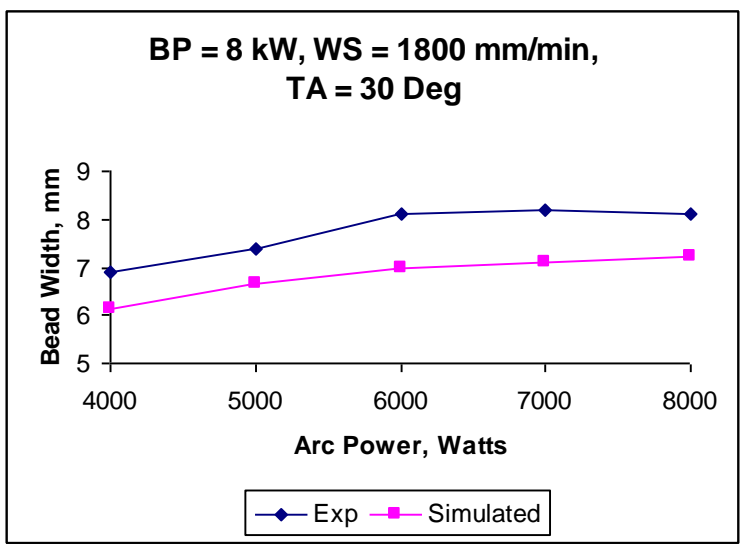

Fig.3.5 Graph showing comparison between Simulated Weld Bead Width with Experimental results

\section{FINITE ELEMENT SIMULATION OF HYBRID WELDING PROCESS FOR WELDING 304 STAINLESS STEEL PLATE}

The finite element model developed for simulation is checked for adequacy and proved to be efficient. So, the model developed can be used for simulating the process using 304 austenitic stainless steel material. The concept of design of experiments was used to develop a design matrix for carrying out the simulation in a systematic way.

\subsection{Design of Experiments}

It is necessary to consider the resources that can be devoted to the experiment and useful to outline the form of the analysis so as to ensure that the experimental data can be analysed in a meaningful way. Paying attention to the way in which results are to be reported is helpful in identifying whether the objectives were clearly formulated. The design of experiments deals with the procedure of selecting number of trials and conditions for running them [2]. DOE involves making a set of representative experiments with regards to a set of input variables. A common approach in DOE is to define an interesting standard reference experiment and then new, representative experiments are performed around it. These new experiments are laid out in a symmetrical fashion around the standard reference experiment. Hence, the standard reference experiment is usually called the center point.

\subsection{Selection Of Design}

As two level factorial technique, either full or fractional type, possess linear response surfaces and they do not estimate curvature effects, a five level factorial technique of response surface design (i.e. central composite rotatable design) was selected for the present study. 


\subsection{Design of Experiments Procedure}

The various steps involved in the design of experiments are, Identifying the important process control variables

Finding the upper and lower limits of the selected control variables

Developing the design matrix

\subsubsection{Identification of Process Control Variables}

As the weld bead dimensions ware the main interest of the study, the process control variables which influence the bead dimensions should be selected as control variables. So, Laser beam power (BP), Arc current (AC), Torch Angle (TA) were identified as control variables.

\subsubsection{Finding the Limits Of The Process Variables}

At least half depth penetration is the criteria of choosing the working ranges of variables. Owing to this condition, the laser beam power range of $6 \mathrm{~kW}-10 \mathrm{~kW}$, arc current range of 300 to 500 amperes and torch angle of 30 to 45 is considered. Using the Response Surface Methodology, the natural variables are transformed into dimensionless coded variables. The upper limit of the factor is coded as +1.682 and the lower limit as -1.682 , the coded values for intermediate ranges are then calculated from the following relationship:

$X_{i}=1.682\left[2 X-\left(X_{\max }+X_{\min }\right)\right] /\left[X_{\max }-X_{\min }\right]$

Where,

$X_{i} \quad$ - the required coded value of a variable $X$;

$\mathrm{X}$ - any value of the variable from $\mathrm{X}_{\max }$ to $\mathrm{X}_{\text {min }}$;

$X_{\text {min }}$ - the lower level of the variable

$\mathrm{X}_{\max }$ - the upper level of the variable.

The decided levels of the selected process parameters with their units and notations are given in Table 4.1

Table 4.1- Control factors and its levels (three factors - five levels)

\begin{tabular}{|c|c|c|c|c|c|c|c|}
\hline \multirow[b]{2}{*}{$\begin{array}{c}\text { Fact } \\
\text { or }\end{array}$} & \multirow[b]{2}{*}{ Units } & \multirow{2}{*}{$\begin{array}{c}\text { Notati } \\
\text { on }\end{array}$} & \multicolumn{5}{|c|}{ Factor levels } \\
\hline & & & $\begin{array}{c}- \\
1.6 \\
82 \\
\end{array}$ & -1 & 0 & 1 & $\begin{array}{l}1.6 \\
82\end{array}$ \\
\hline $\begin{array}{c}\text { Bea } \\
\text { m } \\
\text { powe } \\
\text { r }\end{array}$ & $\mathrm{kW}$ & BP & $\begin{array}{c}6.7 \\
5\end{array}$ & $\begin{array}{c}7.2 \\
5\end{array}$ & 8 & $\begin{array}{c}8.7 \\
5\end{array}$ & $\begin{array}{c}9.2 \\
5\end{array}$ \\
\hline $\begin{array}{c}\text { Arc } \\
\text { curre } \\
\text { nt }\end{array}$ & amps & $\mathrm{AC}$ & 300 & $\begin{array}{c}32 \\
5\end{array}$ & $\begin{array}{c}37 \\
5\end{array}$ & $\begin{array}{c}42 \\
5\end{array}$ & 450 \\
\hline $\begin{array}{c}\text { Torc } \\
\mathrm{h} \\
\text { angle }\end{array}$ & $\begin{array}{c}\text { Degre } \\
\text { es }\end{array}$ & BA & 30 & $\begin{array}{c}32 . \\
5\end{array}$ & $\begin{array}{c}37 . \\
5\end{array}$ & $\begin{array}{c}42 . \\
5\end{array}$ & 45 \\
\hline
\end{tabular}

BP- Beam power, AC- Arc current, TA- Torch angle

\subsubsection{Development Of Design Matrix}

In factorial design, the experiments are conducted for all possible combinations of the parameter levels and these combinations, are written in the form of a table, where the rows correspond to different trials and the columns to the levels of the parameters, form a design matrix. The selected design matrix is shown in Table 4.3. It is a three factor five level central composite rotatable design consisting of 20 sets of coded conditions composed of a full factorial $23=8$ plus 6 centre points and 6 star points. In this matrix, twenty simulation runs provide ten estimates for the effect of three parameters.

\subsection{Finite Element Model For Trail Runs}

The Finite element model of dimensions 100mm X 440mm X $10 \mathrm{~mm}$ is used. The AISI 304 austenitic stainless steel material is considered for the simulations to be carried out. The temperature dependent thermal properties for AISI 304 stainless steel material are given in Table 4.2. These properties were taken from the work carried out by Chang and $\mathrm{Na}$ [1].

Table 4.2 Temperature dependent thermal properties for AISI 304 Austenitic stainless steels

\begin{tabular}{|c|c|c|c|c|}
\hline $\begin{array}{c}\text { Temp } \\
\text { ( K ) }\end{array}$ & $\begin{array}{c}\text { Thermal } \\
\text { Conductivity, } \\
\mathbf{W} / \mathbf{m}^{\mathbf{0}} \mathbf{K}\end{array}$ & $\mathbf{K g} / \mathbf{~ m}^{\mathbf{3}}$ & $\begin{array}{c}\text { Density } \\
\mathbf{J} / \mathbf{~ K g ~ K e} \mathbf{K}\end{array}$ & $\begin{array}{c}\text { Conv. } \\
\text { Coefficient, } \\
\mathbf{W} / \mathbf{m}^{\mathbf{2}} \mathbf{K}\end{array}$ \\
\hline 200 & 11 & 8200 & 350 & 8.51 \\
\hline 400 & 15.5 & 8000 & 400 & 25.97 \\
\hline 600 & 19 & 7800 & 440 & 49.9 \\
\hline 800 & 22.5 & 7600 & 550 & 79.3 \\
\hline 1000 & 26 & 7500 & 590 & 113.58 \\
\hline 1200 & 30 & 7400 & 610 & 152.33 \\
\hline 1400 & 34.5 & 7350 & 640 & 192.24 \\
\hline 1600 & 39.5 & 7300 & 680 & 242.07 \\
\hline 1800 & 44 & 7200 & 720 & 292.61 \\
\hline 2000 & 47 & 7200 & 760 & 346.71 \\
\hline
\end{tabular}

The Simulations are carried out for 20 trails according to the design matrix by adopting the procedure discussed in section 3.2. Weld bead dimensions were determined from the simulated bead profiles obtained from ANSYS 10. The transverse sections were cut using /CPLANE option available in it. The design matrix and the measured responses are shown in Tables 4.3. 
Table 4.3 Design Matrix and simulated values of bead geometry

\begin{tabular}{|l|r|r|r|c|c|}
\hline Sl. No & \multicolumn{3}{|c|}{ Design Matrix } & \multicolumn{2}{l|}{ Bead Parameters } \\
\hline & \multicolumn{1}{|c|}{ BP } & \multicolumn{1}{|c|}{ AC } & TA & $\begin{array}{c}\text { DP, } \\
\text { mm }\end{array}$ & $\begin{array}{c}\text { BW, } \\
\text { mm }\end{array}$ \\
\hline 1 & -1 & -1 & -1 & 6.364 & 8.48 \\
\hline 2 & 1 & -1 & -1 & 6.945 & 9.12 \\
\hline 3 & -1 & 1 & -1 & 6.485 & 9.493 \\
\hline 4 & 1 & 1 & -1 & 6.98 & 9.592 \\
\hline 5 & -1 & -1 & 1 & 6.407 & 8.346 \\
\hline 6 & 1 & -1 & 1 & 6.934 & 8.612 \\
\hline 7 & -1 & 1 & 1 & 6.479 & 9.436 \\
\hline 8 & 1 & 1 & 1 & 7.00 & 9.571 \\
\hline 9 & -1.682 & 0 & 0 & 6.381 & 8.391 \\
\hline 10 & 1.682 & 0 & 0 & 7.12 & 9.167 \\
\hline 11 & 0 & -1.682 & 0 & 6.692 & 8.136 \\
\hline 12 & 0 & 1.682 & 0 & 6.725 & 9.721 \\
\hline 13 & 0 & 0 & -1.682 & 6.744 & 9.07 \\
\hline 14 & 0 & 0 & 1.682 & 6.739 & 9.09 \\
\hline 15 & 0 & 0 & 0 & 6.743 & 9.07 \\
\hline 16 & 0 & 0 & 0 & 6.743 & 9.07 \\
\hline 17 & 0 & 0 & 0 & 6.743 & 9.07 \\
\hline 18 & 0 & 0 & 0 & 6.743 & 9.07 \\
\hline 19 & 0 & 0 & 0 & 6.743 & 9.07 \\
\hline 20 & 0 & 0 & 0 & 6.743 & 9.07 \\
\hline
\end{tabular}

\section{RESULTS AND DISCUSSION}

Simulations were performed by varying the parameters of beam power, Arc Current and MIG torch angle. Figures 5.1 and 5.2 show the three dimensional view of temperature distribution for trials 1 and 8 . The maximum temperature obtained is higher for the trial 8 as the beam power and Arc Current are higher. Figures 5.3 and 5.4 depict the transverse sectional view of the plates at $20 \mathrm{~mm}$ from the end showing various temperature isotherms. Transverse sections were taken using /CPLANE option available in ANSYS 10.

Figures 5.5 and 5.6 show the melting temperature isotherm for both trial 1 and trial 8 . The predicted depth of penetration is higher for trail 8 than trail 1 because more beam power is used in trial 8. From the simulated bead profile the depth of penetration and bead width are obtained.

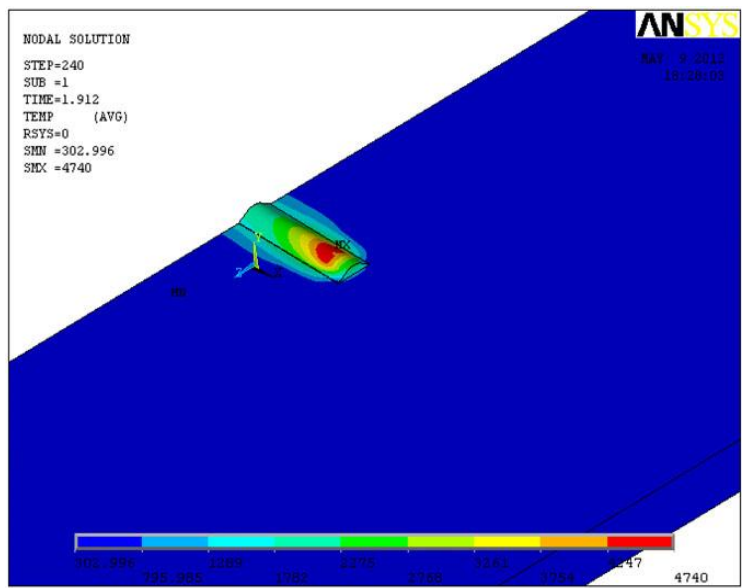

Fig5.1 Temperature contour plot for bead on plate weld (trial 1)

Figures 5.7 and 5.8 show the time history plot for six successive nodes along the welding direction from the end of the plate which show the temperatures at specific location (nodes) as the function of time. From the figures it is found that the temperature increases as the heat source approaches the respective node and once the heat source crosses the node the temperature decreases and gradually reduces to room temperature.

Figures 5.9 and 5.10 show temperature distribution along the width of the plate for trials 1 and 8 respectively which are obtained at the starting location when the heat source is 20 $\mathrm{mm}$ ahead of the location. These figures show a narrow zone of temperature rise that indicate the smaller heat affected zone.

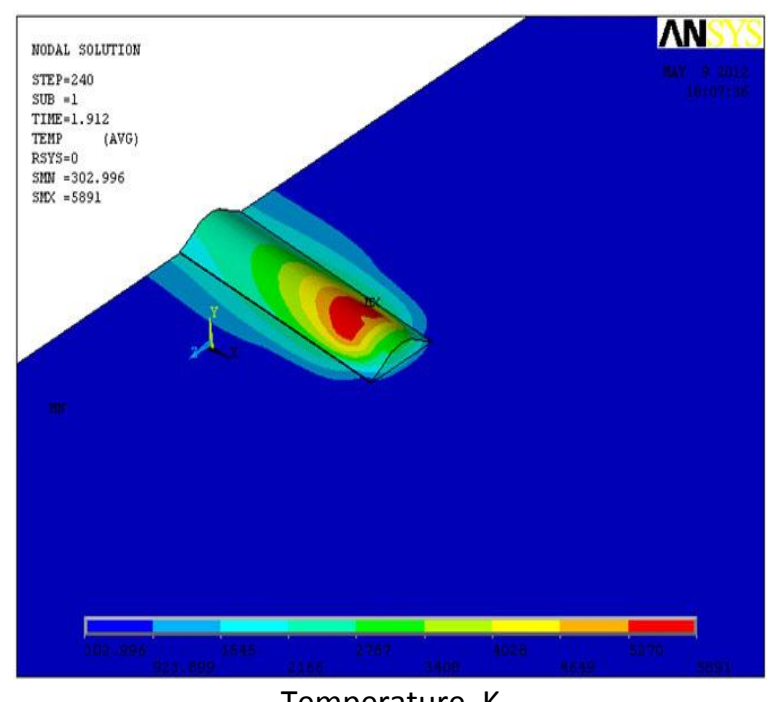

Temperature, $\mathrm{K}$

Fig.5.2 Temperature contour plot for bead on plate weld (trial 8) 


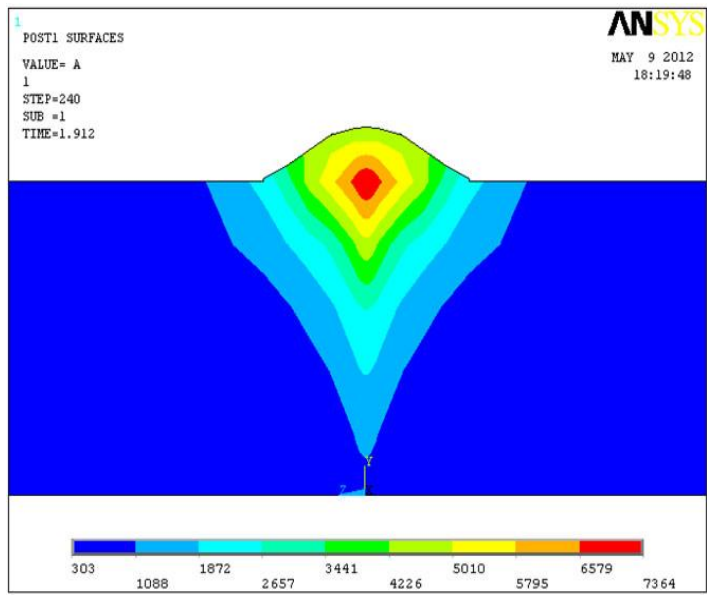

Fig. 5.3 Transverse sectional view with various temperature isotherms at $20 \mathrm{~mm}$ from the end of the plate (trial 1)

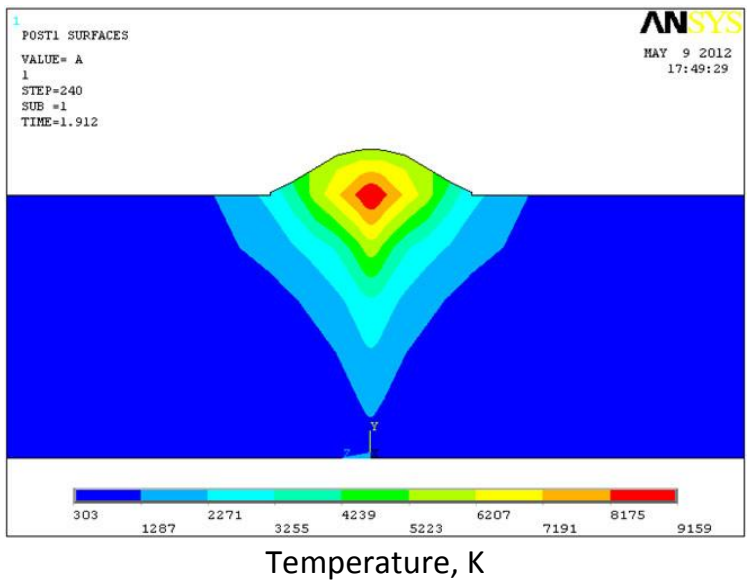

Fig.5.4 Transverse sectional view with various temperature isotherms at $20 \mathrm{~mm}$ from the end of the plate (trial 8)

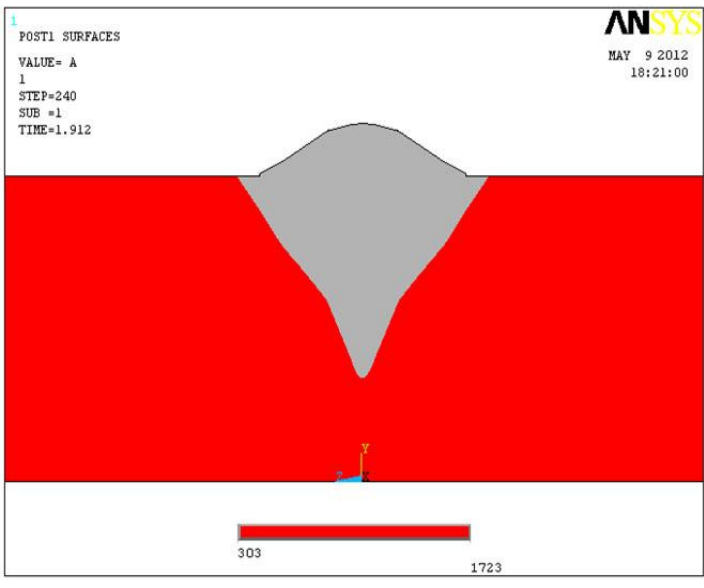

Temperature, $\mathrm{K}$

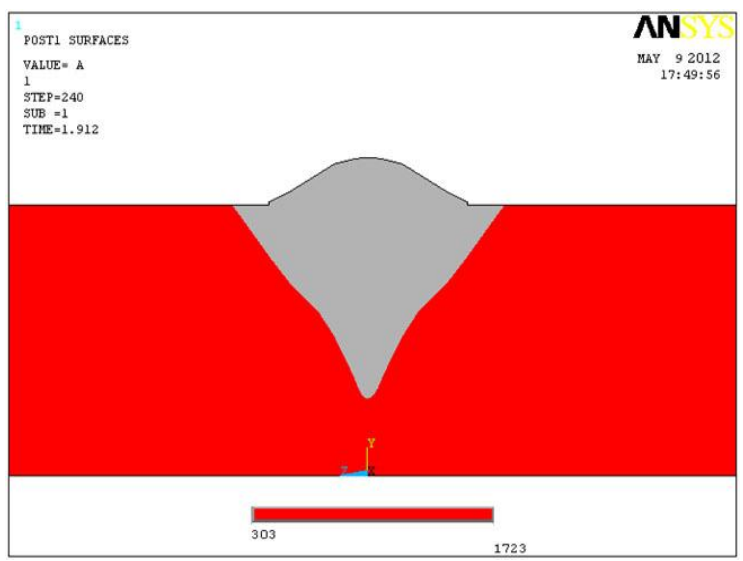

Fig. 5.5 Simulated weld bead profile (trial 1)

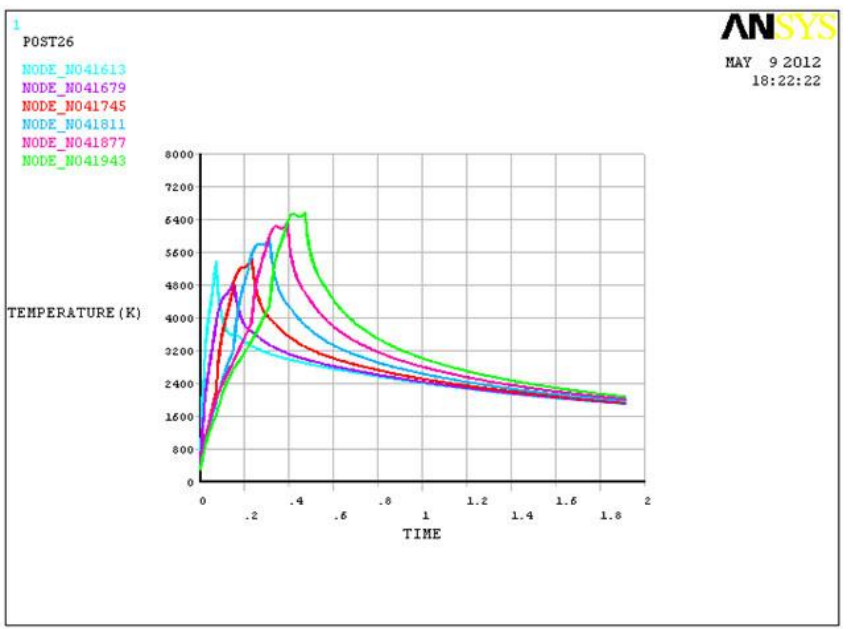

Fig.5.7 Time history plot for successive nodes along weld line (trial 1)

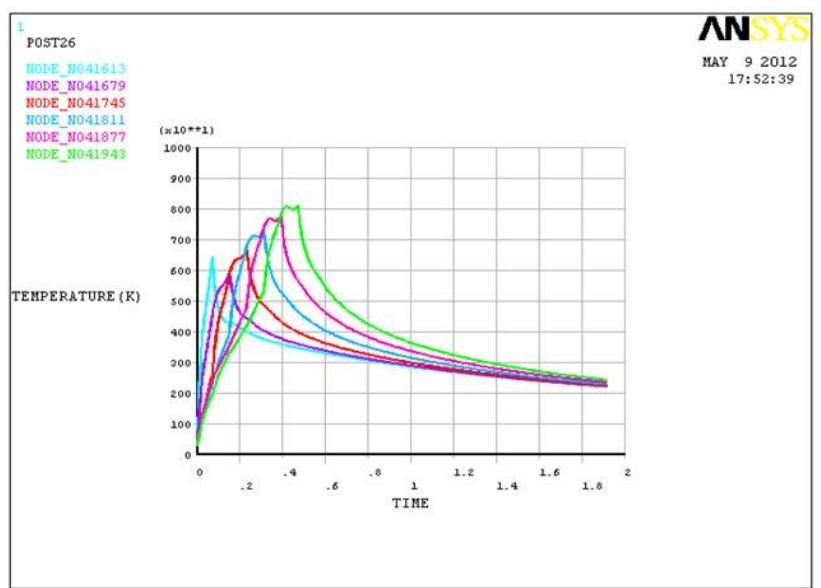

Fig. 5.8 Time history plot for successive nodes along weld line (trial 8)

Fig. 5.6 Simulated weld bead profile (trial 8) 


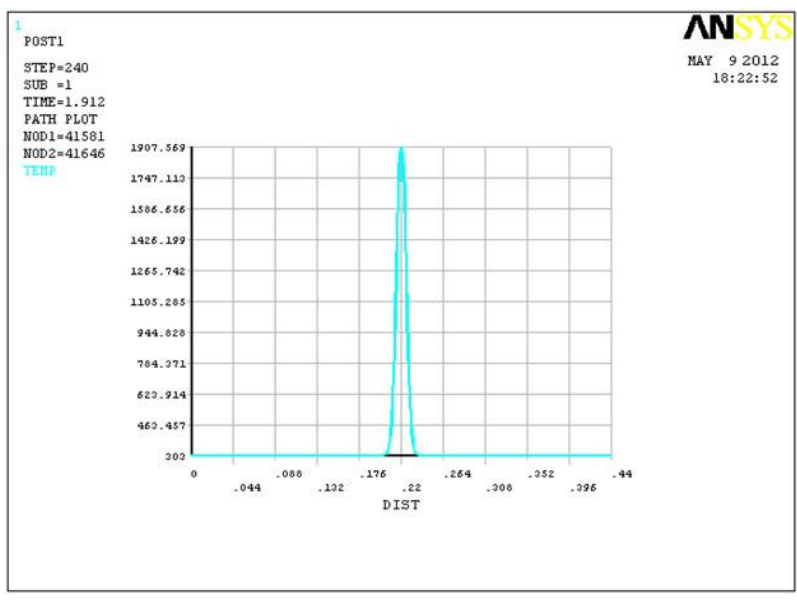

Fig. 5.9 Temperature distribution along the width of the plate when the beam is $20 \mathrm{~mm}$ ahead (trial 1)

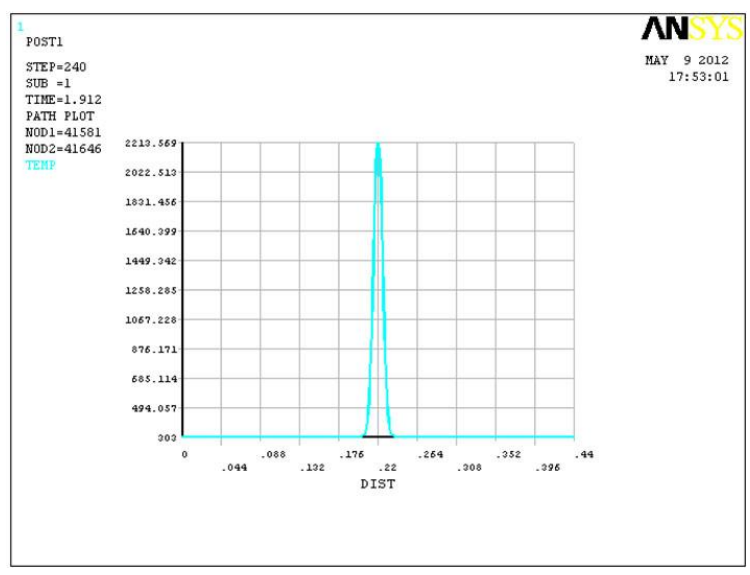

Fig. 5.10 Temperature distribution along the width of the plate when the beam is $20 \mathrm{~mm}$ ahead (trial 8)

\section{CONCLUSIONS}

The following conclusions were arrived at after analyzing the various aspects of Hybrid welding process for welding of AISI 304 austenitic stainless steels sheets.

- The Hybrid Welding process was simulated using ANSYS 10 Software.

- APDL code was developed to carry out the simulations in ANSYS.

- The developed code was validated with the Experimental Analysis and a good agreement was arrived.

- A design matrix was developed by identifying proper control variables and bead dimensions were obtained from the simulations using ANSYS.

- The FEA model was simulated as per the designed matrix and various temperature contours, timetemperature history plots, melting point isotherms for weld bead profile were obtained.
- Mathematical equations were developed for responses in weld bead dimensions with variables like Beam power, Arc current, Torch angle using SYSTAT 11 software.

\section{REFERENCES:}

[1] D. Travis, G. Dearden, K.G. Watkins, 'Sensing for Monitoring of the Laser-GMAW Hybrid Welding Process', Proceedings of 23rd International Congress on Applications of Lasers \& Electro- Optics, Sanfrancisco, California, Laser Institute of America Publications No 597, paper no 206 Vol.97(2004).

[2] Paul Denney, Dennis Harwig, Larry Brown, 'TechnologyDevelopment, Deployment, Education and Training', Proceedings of 2001 Ship Production Symposium and Expo, Ypsilanti, Michigan, June 14-15, Edison Welding Institute, Project No.: S09782001, June 14-15, 2001.

[3] P.C. Wang, R.J. Menassa, S.P. Marin, 'Modeling of Hybrid Laser-MIG Keyhole Welding Process (1001)', Proceedings of IMECE'03, 2003 ASME International Mechanical Engineering Congress \& Exposition, Washington, D.C., IMECE2003-41763, November 16-21, 2003.

[4] G. Campana, A. Fortunato, A. Ascari, G. Tani, L. Tomesani, 'The Influence of Arc transfer mode in Hybrid Laser-MIG welding', Journal of Materials Processing Technology, pp 1-6, 2007.

[5] Gang Songa, Liming Liu , Peichong Wang, 'Overlap welding of magnesium AZ31B sheets using laser-arc hybrid process', Journal Materials Science and Engineering A 429, pp312-319, 2006.

[6] MS Thesis by Prof. Marc Wouters, 'An investigation of geometrical considerations of Hybrid Laser-MIG welding', Division of Manufacturing Systems Engineering, Luleå University of Technology Luleå, Sweden Luleå, November 2005.

[7] P.C. Wang, R.J. Menassa, S.P. Marin, 'Modeling of Hybrid Laser-MIG Keyhole Welding Process (1001)', Proceedings of IMECE'03, 2003 ASME International Mechanical Engineering Congress \& Exposition, Washington, D.C., IMECE2003-41763, November 16-21, 2003.

[8] M M Mahapatra, G L Datta*, and B Pradhan, 'Threedimensional finite element analysis to predict the effects of shielded metal arc welding process parameters on temperature distributions and weldment 